\title{
Optimal design of Stirling heat engine using an advanced optimization algorithm
}

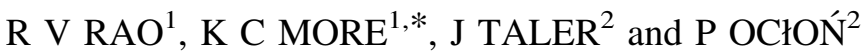 \\ ${ }^{1}$ Department of Mechanical Engineering, S.V. National Institute of Technology, Surat 395007, India \\ ${ }^{2}$ Instytut Maszyn i Urządzeń Energetycznych, Politechnika Krakowska, Al. Jana Pawła II 37, 31-864 Kraków, \\ Poland \\ e-mail: kiran.imagine67@gmail.com
}

MS received 9 March 2015; revised 20 April 2016; accepted 23 May 2016

\begin{abstract}
The Stirling engine presents an excellent theoretical output equivalent to the output of Carnot engine and it is less pollutant and requires little maintenance. In this paper, Stirling heat engine is considered for optimization with multiple criteria. A recently developed advanced optimization algorithm namely "teachinglearning-based optimization (TLBO) algorithm" is used for maximization of output power, minimization of pressure losses and maximization of the thermal efficiency of the entire solar Stirling system. The comparisons of the proposed algorithm are made with those obtained by using the decision-making methods like linear programming technique for multi-dimensional analysis of preference (LINMAP), technique for order of preference by similarity to ideal solution (TOPSIS) and fuzzy Bellman-Zadeh method that have used the Pareto frontier gained through non-dominated sorting genetic algorithm-II (NSGA-II). The comparisons were also made with those obtained by the experimental results. It is found that the TLBO algorithm has produced comparatively better results than those given by the decision-making methods and the experimental results presented by the previous researchers.
\end{abstract}

Keywords. Stirling heat engine; multi-objective optimization; thermal efficiency; pressure loss; teachinglearning-based optimization algorithm.

\section{Introduction}

The Stirling engine has huge prospective to be useful for exchanging heat into the mechanical effort with a high thermal efficiency. Its thermal efficiency might be as high as the Carnot efficiency. Stirling engine can be powered by different heat sources and waste heat. It can utilize compressible fluid as a working fluid. The schematic diagram of Stirling engine is shown in figure 1 [1]. The compression and expansion processes of the cycle take place in power cylinder with a power piston. A displacer piston shuttles the working fluid back and forth the heater, regenerator and cooler at constant volume. For providing a closed engine chamber, the gas circuit of displacer piston is closed using the tubes. The displacer and the power piston have same dimensions. In mono-phase operation, the power piston contacts the engine chamber pressure on one side and ambient pressure on the other side.

The Stirling engine has three dissimilar configurations namely alpha, beta and gamma configurations and is shown in figure 2 [2]. Markman et al [3] conducted an experiment using the beta-configuration of the Stirling engine to

*For correspondence determine the parameters of a $200 \mathrm{~W}$ Stirling engine by measuring the thermal-flux and mechanical-power losses to maximize the engine efficiency. Orunov et al [4] presented a method to calculate the optimum parameters of a singlecylinder Stirling engine for maximizing the efficiency. Abdalla and Yacoub [5] used saline feed raw water as the cooling water and had improved the thermal efficiency of the Stirling engine. Hirata et al [6] evaluated the performance of a small $100 \mathrm{~W}$ displacer-type Stirling engine Ecoboy-SCM81. An analysis model using an isothermal method considering the pressure loss in the regenerator, the buffer space loss, and the mechanical loss of the prototype engine, was developed to improve the engine performance.

Costea and Feidt [7] studied the effect of variation of the overall heat transfer coefficient on the optimum distribution of the heat transfer surface conductance or areas of the Stirling engine heat exchanger. Wu et al [8] analyzed the optimal performance of a Stirling engine. The influences of heat transfer, regeneration time and imperfect regeneration on the optimal performance of the irreversible Stirling engine cycle were discussed. In another work, Wu et al [9] showed that the quantum Stirling cycle was different from the classical thermodynamic one because of different characters of the working fluids. The authors had studied 


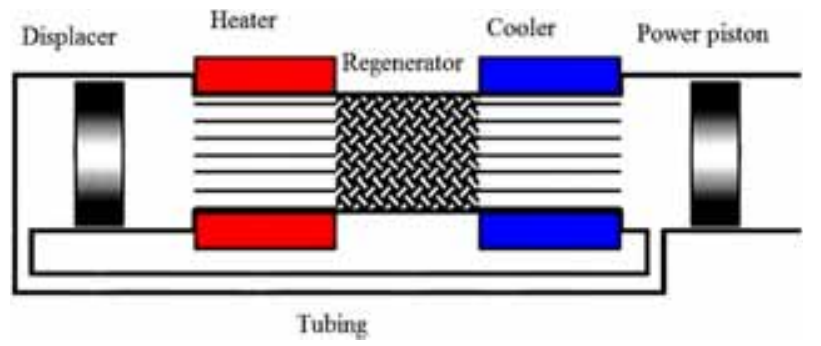

Figure 1. Schematic diagram of the Stirling engine [1].

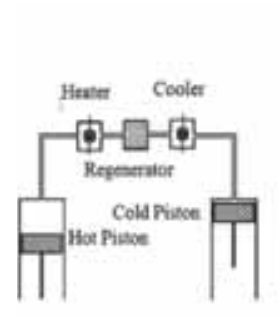

(a)

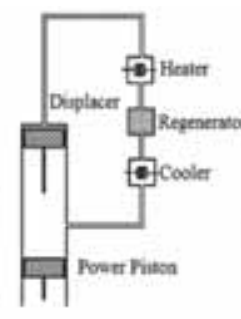

(b)

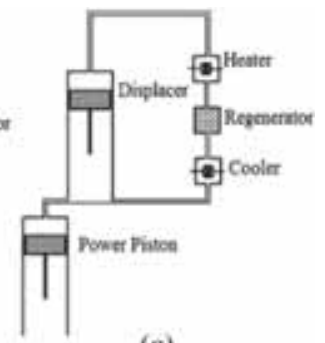

(c)
Figure 2. Basic mechanical configurations for Stirling engine. (a) Alpha-configuration. (b) Beta-configuration. (c) Gamma-configuration [2].

the optimal performance of forward and reverse quantum Stirling cycles. Costea et al [10] studied the finite speed of the piston; friction and throttling in the regenerator to validate the design of a solar Stirling engines.

$\mathrm{Wu}$ et al [11] presented the finite-time exergoeconomic optimal performance of a quantum Stirling engine. The maximum exergoeconomic profit, the optimal thermal efficiency and power output corresponding to performance bound of an endoreversible quantum Stirling engine were presented. Organ [12] presented the optimization of Stirling engine regenerator using the effects of various parameters such as diameter, length and materials on regenerator performance, irreversibility, and temperature gradient. Kaushik and Kumar [13] investigated the finite time thermodynamic analysis of an endoreversible Stirling heat engine and used finite time thermodynamics to optimize the power output and the corresponding thermal efficiency of the endoreversible Stirling heat engine. In another study, Kaushik and Kumar [14] applied finite time thermodynamics to optimize the power output and the corresponding thermal efficiency of an irreversible Ericsson and Stirling heat engines.

$\mathrm{Gu}$ et al [15] attempted to design a high efficiency Stirling engine using a composite working fluid, e.g. twocomponent fluid: gaseous carrier and phase-change component and single multi-phase fluid, together with supercritical heat recovery process. Hsu et al [16] studied the integrated system of a free-piston Stirling engine and an incinerator. The efficiency and the optimal power output, including the effect induced by internal and external irreversibility were described. Petrescu et al [17] presented a method to calculate the efficiency and power of a Stirling engine. The method was based on the first law of thermodynamics for processes with finite speed and the direct method for closed systems.

Martaj et al [18] studied the thermodynamic analysis of a low temperature differential Stirling engine at steady state operation, and energy, entropy and exergy balances. Timoumi et al [19] developed a numerical model based on lumped analysis approach. Formosa and Despesse [20] implemented an isothermal model for presenting engine power output and efficiency due to dead volume. Li et al [21] optimized the absorber temperature and corresponding thermal efficiency and developed a mathematical model for the overall thermal efficiency of solar-powered high temperature differential dish Stirling engine. Tlili [22] studied the effects of regenerating effectiveness and heat capacitance rate of external fluids in heat source/sink at maximum power and efficiency.

Ahmadi et al [23] used NSGA-II algorithm for optimization of Stirling heat engine. Maximization of output power and overall thermal efficiency and minimization of the pressure loss were considered as objective functions. Ahmadi et al [24] investigated the optimal power of an endoreversible Stirling cycle with perfect regeneration and genetic algorithm (GA) was used for the optimization of this endoreversible Stirling engine. Ahmadi et al [25] used NSGA-II algorithm for dimensionless thermo-economic optimization of solar dish-Stirling engine. In another work, Ahmadi et al [26] used NSGA-II algorithm for optimization of solar dish-Stirling engine. Maximization of output power and overall thermal efficiency and minimization of the rate of entropy generation were considered as an objective functions.

From the literature review, it is observed that only very few advanced optimization algorithms like GA and NSAGII had been used by the researchers for the optimization of Stirling heat engine. However, these algorithms require tuning of their specific parameters. For example, GA requires crossover probability, mutation probability and a selection operator; NSGA-II requires crossover probability, mutation probability, real-parameter SBX parameter and real-parameter mutation parameter. The proper tuning of the algorithm-specific parameters is very essential factor which affects the performance of the optimization algorithms. The improper tuning of algorithm-specific parameters either increases the computational effort or yields the local optimal solution [27]. In addition to the algorithmspecific parameters of an algorithm, common control parameters such as population size and the number of iterations are to be considered. The common control parameters are common to any population-based algorithm and these also need proper tuning. The designer's burden will be reduced if there is no need to tune at least some of the parameters required by the algorithm. Hence, to overcome the problem of tuning of algorithm-specific 
parameters, a recently developed algorithm-specific parameter-less algorithm known as teaching-learningbased optimization (TLBO) algorithm [28, 29] is used in the present work for the multi-objective optimization of Stirling engine.

Multi-objective optimization has been defined as finding a vector of decision variables, while optimizing (i.e. minimizing or maximizing) several objectives simultaneously, with a given set of constraints. In the present investigation, multi-objective optimization is carried out to achieve the optimization of three objective functions: maximization of output power and the thermal efficiency of the entire solar Stirling system and minimization of pressure losses. The multi-objective optimization is conducted with eleven decision variables including the temperatures of heat source and heat sink and their difference with working fluids, rotation speed, mean effective pressure, stroke, heat source temperature, heat sink temperature, number of gauzes of the matrix, regenerator's length, piston diameter, and regenerator diameter are considered.

In the present work, an attempt is made to see if there is any improvement possible in the design of Stirling engine by using an advanced optimization algorithm known as teaching-learning-based optimization (TLBO) algorithm. The reason for choosing the TLBO algorithm is that it is simple, robust, algorithm-specific parameter-less and gives optimal solutions comparatively with less number of function evaluations and with less computational effort [28]. The TLBO algorithm is applied in the present work for simultaneously optimizing the three objectives considered by Ahmadi et al [23] for the design of Stirling engine.

The next section presents the details of the analysis of the Stirling engine cycle with irreversibilities and the considered design problem.

\section{Analysis of the Stirling engine cycle with irreversibilities}

Stirling cycle consists of four major processes as shown in figure 3 [30]. Process 1-2 is an isothermal process in which the compressing working fluid rejects the heat at
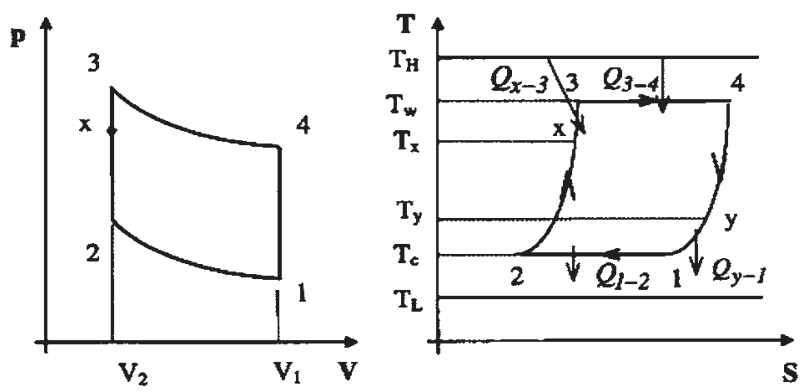

Figure 3. Thermodynamic state diagrams of ideal Stirling cycle [30]. constant temperature $\left(T_{\mathrm{C}}\right)$ to heat sink which has a constant temperature $\left(T_{\mathrm{L}}\right)$. Then the working fluid crosses over the regenerator and is warmed up to $T_{\mathrm{h}}$ in an isochoric process 2-3. In process $3-4$, the working fluid expands at a constant temperature $T_{\mathrm{h}}$, and obtains the heat from the heat source at a constant temperature $\left(T_{\mathrm{H}}\right)$. The last process 4-1 is an isochoric cooling process where the regenerator absorbs heat from the working fluid. In an actual cycle it is impractical to have an ideal heat transfer in the regenerator in which the entire amount of absorbed heat (in process 4-1) is transferred to the working fluid into the isochoric heating process (process 2-3).

The ideal Stirling engine cycle is shown on $p-V$ and $T-S$ diagrams in figure 3 . The $T-S$ diagram is modified to include the effects of heat transfer through a temperature difference at the source and sink and for incomplete regeneration. Additional heat from the external source is shown to be needed in the process, $Q_{x-3}$, due to incomplete regeneration. Similarly, the unregenerated heat is shown being rejected in the process, $Q_{y-1}$. Fluid friction of the gas causes most of the pressure loss as it passes through the regenerator.

The mathematical model presented by Ahmadi et al [23] is considered in the present work and the details are given below.

The pressure losses are presented as $[7,10,17,31]$,

$$
\sum \Delta P_{\mathrm{i}}=\Delta P_{\text {throat }}+\Delta p_{\mathrm{f}}+\Delta p_{\mathrm{w}}
$$

where $\Delta P_{\text {throat }}$ is the pressure drop due to the internal friction produced in the regenerator.

$$
\Delta P_{\text {throat }}=\frac{15}{\gamma}\left[\frac{p_{\mathrm{m}}}{2 R(\tau+1)\left(T_{\mathrm{L}}+\Delta T_{\mathrm{L}}\right)}\right] \cdot N \cdot\left(\frac{D_{\mathrm{c}}^{2}}{N_{\mathrm{R}} D_{\mathrm{R}}^{2}}\right) .
$$

$\Delta p_{\mathrm{f}}$ is the pressure drop due to mechanical resistance of parts of engine and is experimentally found by using the following equation:

$$
\begin{gathered}
\Delta p_{\mathrm{f}}=\frac{\left(0.94+0.0015 s n_{\mathrm{r}}\right) \cdot 10^{5}}{3 \mu^{\prime}}\left(1-\frac{1}{\lambda}\right) . \\
\mu^{\prime}=1-\frac{1}{3 \lambda} .
\end{gathered}
$$

The pressure drop due to the piston speed is given by

$$
\begin{aligned}
\Delta p_{\mathrm{w}}= & \left(\frac{s n_{\mathrm{r}}}{60}\right) \cdot\left(\frac{4 p_{\mathrm{m}}}{(1+\lambda)(1+\tau)}\right)\left(\frac{\lambda \ln \lambda}{\lambda-1}\right) \sqrt{\frac{\gamma}{R}}\left(\frac{1}{\sqrt{T_{\mathrm{L}}+\Delta T_{\mathrm{L}}}}\right) \\
& \times\left[1+\sqrt{\frac{T_{\mathrm{H}}-\Delta T_{\mathrm{H}}}{T_{\mathrm{L}}+\Delta T_{\mathrm{L}}}}\right] .
\end{aligned}
$$

$\Delta Q_{\mathrm{R}}$ is heat loss through two regenerative processes in the cycle and is calculated as 


$$
\Delta Q_{\mathrm{R}}=m_{\mathrm{g}} C_{\mathrm{vg}} X\left(T_{\mathrm{H}}-\Delta T_{\mathrm{H}}-T_{\mathrm{L}}-\Delta T_{\mathrm{L}}\right) .
$$

The heat released between heat source and working fluid $\left(Q_{\mathrm{h}}\right)$ is given by

$$
\begin{aligned}
Q_{\mathrm{h}}= & m_{\mathrm{g}}\left(1-\frac{\Delta p_{\mathrm{w}} \cdot(\lambda+1)(\tau+1)}{4 p_{\mathrm{m}}}-\frac{b \Delta p_{\text {throat }}}{2 p_{\mathrm{m}}}-\frac{f \Delta p_{\mathrm{f}}}{p_{\mathrm{m}}}\right) \\
& \times R\left(T_{\mathrm{H}}-\Delta T_{\mathrm{H}}\right) \ln \lambda .
\end{aligned}
$$

The net heat released from heat source $\left(Q_{\mathrm{H}}\right)$ is given by

$$
Q_{\mathrm{H}}=Q_{\mathrm{h}}+\Delta Q_{\mathrm{R}}
$$

The pure flux transferred to working fluid is

$$
\underset{\mathrm{H}}{\dot{Q}}=\left(Q_{\mathrm{h}}+\Delta Q_{\mathrm{R}}\right) \frac{n_{\mathrm{r}}}{60} .
$$

Substituting Eqs. (6-8) into Eq. (9):

$$
\begin{aligned}
& Q_{\mathrm{H}}=\left[\left(1-\frac{\Delta p_{\mathrm{w}}(\lambda+1)(\tau+1)}{4 p_{\mathrm{m}}}-\frac{b \Delta p_{\text {throat }}}{2 p_{\mathrm{m}}}-\frac{f \Delta p_{\mathrm{f}}}{p_{\mathrm{m}}}\right)\right. \\
& \left.\quad \times R\left(T_{\mathrm{H}}-\Delta T_{\mathrm{H}}\right) \ln \lambda+X m_{\mathrm{g}} C_{\mathrm{vg}}\left(T_{\mathrm{H}}-\Delta T_{\mathrm{H}}-T_{\mathrm{L}}-\Delta T_{\mathrm{L}}\right)\right] \frac{n_{\mathrm{r}}}{60} .
\end{aligned}
$$

The output power of engine is given by $[17,31]$ :

$$
\begin{gathered}
\text { power }=\eta \dot{Q}_{\mathrm{H}}=\left(1-\frac{T_{\mathrm{L}}+\Delta T_{\mathrm{L}}}{T_{\mathrm{H}}-\Delta T_{\mathrm{H}}}\right) \cdot \eta_{\mathrm{I}, \mathrm{irr}} \dot{Q}_{\mathrm{H}} \cdot \\
\Delta T_{\mathrm{L}}=T_{\mathrm{c}}-T_{\mathrm{L}} . \\
\Delta T_{\mathrm{H}}=T_{\mathrm{H}}-T_{\mathrm{h}} . \\
\eta_{\mathrm{c}}=\left(1-\frac{T_{\mathrm{L}}+\Delta T_{\mathrm{L}}}{T_{\mathrm{H}}-\Delta T_{\mathrm{H}}}\right) .
\end{gathered}
$$

By substituting Eqs. (12-14) in Eq. (11), we have

$$
\begin{gathered}
\eta=\eta_{\mathrm{c}} \eta_{\mathrm{II}, \mathrm{irr}} \cdot \\
\text { power }=\eta_{\mathrm{c}} \eta_{\mathrm{II}, \mathrm{irr}} \underset{\mathrm{H}}{\dot{Q}},
\end{gathered}
$$

where $\eta_{\mathrm{c}}$ is Carnot efficiency and $\eta_{\mathrm{II}, \text { irr }}$ is the second law efficiency and is given by

$$
\eta_{\mathrm{II}, \mathrm{irr}}=\eta_{\mathrm{II}, \mathrm{irr}(\mathrm{X})} \cdot \eta_{\mathrm{II}, \mathrm{irr}(\Delta \mathrm{p})} \cdot
$$

The deficient regenerating is calculated as

$$
\eta_{\mathrm{II}, \operatorname{irr}(\mathrm{X})}=\frac{1}{1+\left(\frac{(X)}{((\gamma-1) \ln \lambda)}\right) \cdot \eta_{\mathrm{c}}}
$$

with

$$
X=y X_{1}+(1-y) X_{2},
$$

where $y$ is the second adjusting coefficient and $X_{1}, X_{2}$ are the regenerative losses coefficient values representing "optimistic" and "pessimistic" evaluation respectively. The value of $y=0.72$ allowed for better match between the analytical and experimental results [7, 10, 17, 31]: In Eq. (19),

$$
\begin{gathered}
X_{1}=\frac{1+2 M+e^{-B}}{2(1+M)} . \\
X_{2}=\frac{M+e^{-B}}{1+M} . \\
M=\frac{m_{\mathrm{g}} C_{\mathrm{vg}}}{m_{\mathrm{R}} C_{\mathrm{R}}} . \\
m_{\mathrm{R}}=\frac{\pi^{2} D_{\mathrm{R}}^{2} L d \rho_{\mathrm{st}}}{16(b+d)} . \\
B=(1+M) \cdot \frac{h A_{\mathrm{R}}}{m_{\mathrm{g}} C_{v_{\mathrm{g}}}} \cdot \frac{30}{n_{\mathrm{r}}} .
\end{gathered}
$$

The convection coefficient $h$ is computed as

$$
h=\frac{0.395\left(\frac{4 p_{\mathrm{m}}}{R T_{\mathrm{L}}}\right) \cdot\left(\frac{s . n_{\mathrm{r}}}{30}\right)^{0.424} C_{\mathrm{p}} v^{0.576}}{(1+\tau)\left[1-\frac{(\pi)}{\left.\left(4\left[\frac{b}{d}\right)+1\right]\right)}\right] \cdot D_{\mathrm{R}}^{0.576} \operatorname{Pr}^{0.667}} .
$$

On the other hand,

$$
A_{\mathrm{R}}=\frac{\pi^{2} D_{\mathrm{R}}^{2} L}{4(b+d)} .
$$

The effect of mechanical friction, piston speed and pressure drop in regenerator are calculated as

$$
\begin{gathered}
\eta_{\mathrm{II}, \operatorname{irr}(\Delta \mathrm{p})}=1-\frac{3 \mu^{1} \cdot \sum \frac{\Delta p_{\mathrm{i}}}{p_{1}}}{\eta^{\prime} \cdot\left(\frac{T_{\mathrm{H}}-\Delta T_{\mathrm{H}}}{T_{\mathrm{L}}+\Delta T_{\mathrm{L}}}\right) \cdot \ln \lambda} . \\
\eta^{\prime}=\eta_{\mathrm{II}, \operatorname{irr}(\mathrm{X}) \cdot \eta_{\mathrm{C}} \cdot} \\
p_{1}=\frac{4 p_{\mathrm{m}}}{(1+\lambda)(1+\tau)} .
\end{gathered}
$$

The above analysis shows that the pressure losses and their effect on the efficiency and output power of the engine depend on the piston speed and are thereby to the engine rotational speed.

Three objective functions considered for the present study are the same as those considered by Ahmadi et al [23] and these are: system pressure losses $\left(\sum \Delta p_{\mathrm{i}}\right)$, the output power (Power) and the Stirling engine thermal efficiency $(\eta)$. The number of decision variables is also same as those considered by Ahmadi et al [23] and these are given as: engine's rotation speed $\left(n_{\mathrm{r}}\right)$; mean effective pressure $\left(P_{\mathrm{m}}\right)$; stroke $(s)$; temperature of heat source $\left(T_{\mathrm{H}}\right)$; temperature of 
heat sink $\left(T_{\mathrm{L}}\right)$; temperature difference between heat source and working fluid $\left(\Delta T_{\mathrm{L}}\right)$; temperature difference between heat sink and working fluid $\left(\Delta T_{\mathrm{H}}\right)$; number of gauzes of the matrix $\left(N_{\mathrm{R}}\right)$; regenerator's length $(L)$; piston diameter $\left(D_{\mathrm{C}}\right)$; and regenerator diameter $\left(D_{\mathrm{R}}\right)$.

The constraints are nothing but the ranges of variables and are given by

$$
\begin{gathered}
1200 \leq n_{\mathrm{r}} \leq 3000 \mathrm{rpm} . \\
0.69 \leq P_{\mathrm{m}} \leq 6.89 \mathrm{MPa} . \\
0.06 \leq S \leq 0.1 \mathrm{~m} . \\
800 \leq T_{\mathrm{H}} \leq 1300 \mathrm{~K} . \\
288 \leq T_{\mathrm{L}} \leq 360 \mathrm{~K} . \\
64.2 \leq \Delta T_{\mathrm{H}} \leq 237.6 \mathrm{~K} . \\
5 \leq \Delta T \leq 25 \mathrm{~K} . \\
250 \leq N_{\mathrm{R}} \leq 400 . \\
6 \times 10^{-3} \leq L \leq 73 \times 10^{-3} . \\
0.05 \leq D_{\mathrm{c}} \leq 0.14 \mathrm{~m} . \\
0.02 \leq D_{\mathrm{R}} \leq 0.06 \mathrm{~m} .
\end{gathered}
$$

The values of the constraints are in a way somewhat arbitrary, in the sense that other aspects which need to be considered like those from fabrication viewpoint are not given due importance. Especially, the upper value of temperature $\left(T_{\mathrm{H}}=1300 \mathrm{~K}\right)$ puts a severe constraint on the selection of material of construction for the hot end of the engine (heat absorbing part/heat receiver). The designer has to be careful while deciding the values of the constraints. However, the constraints represented by Eqs. (30-40) were considered by Ahmadi et al [23] and hence, the same constraints are considered in the present work for making fair comparison.

The next section presents the details of the TLBO algorithm.

\section{Teaching-learning-based optimization algorithm}

Teaching-learning-based optimization (TLBO) algorithm is a teaching-learning process inspired algorithm proposed by Rao et al [29] based on the effect of influence of a teacher on the output of learners in a class. The algorithm mimics the teaching-learning ability of teachers and learners in a classroom. Teacher and learners are the two vital components of the algorithm and describe two basic modes of the learning, through teacher (known as teacher's phase) and interacting with the other learners (known as learner's phase).
The output in TLBO algorithm is considered in terms of results or grades of the learners which depend on the quality of teacher. So, teacher is usually considered as a highly learned person who trains learners so that they can have better results in terms of their marks or grades. Moreover, learners also learn from the interaction among themselves which also helps in improving their results. TLBO is a population-based method and a group of learners is considered as population and different design variables are considered as different subjects offered to the learners and learners' result is analogous to the "fitness" value of the optimization problem. In the entire population, the best solution is considered as the teacher. The flowchart of TLBO algorithm is shown in figure 4 [32]. The working of TLBO is divided into two parts, "teacher phase" and "learner phase". For more details on TLBO algorithm and its code, one may refer to https://sites.google.com/site/ tlborao and Rao [28].

Like many population-based optimization algorithms, the TLBO algorithm also requires certain population size and number of iterations (but it does not have any algorithmspecific parameters to tune and hence, the burden on the designer to tune the algorithm-specific parameters is relieved). Improper selection of population size and number of iterations may also lead to sub-optimal solutions. The population size and number of iterations affect the performance of the algorithm and hence to get optimal values of the design variables and thereby the objective functions, one has to execute the optimization algorithm with different population sizes and number of iterations. In this paper, after conducting various trials, it has been observed that a population size of 50 and 40 number of iterations have given the optimal results of the design variables (and thereby the optimum values of the objective functions). The number of function of evaluations required by TLBO algorithm to achieve optimum solution is equal to 4000 (i.e. $2 \times 40 \times 50$ as the evaluations are done in both the teacher's and learner's phases). The same optimum results are obtained for increased number of function evaluations also. However, less number of function evaluations reduces the computational time and effort.

In this paper, the TLBO algorithm is applied for the design optimization of Stirling heat engine. The three objectives are combined into scalar objective via a weight vector. For this problem, the combined objective function $(Z)$ is defined as follows:

$$
\begin{aligned}
& \text { Maximize } \\
& \quad Z=w_{1} \times Z_{1} / Z_{1 \max }+w_{2} \times Z_{2} / Z_{2 \max }-w_{3} \times Z_{3} / Z_{3 \min },
\end{aligned}
$$

where $Z_{1}, Z_{2}$ and $Z_{3}$ are the objective functions of power, efficiency and pressure loss respectively and $w_{1}, w_{2}$ and $w_{3}$ are the weights given to the objective functions 1,2 and 3 respectively. The designer can give any weight to the objective functions. But the condition is that summation of 


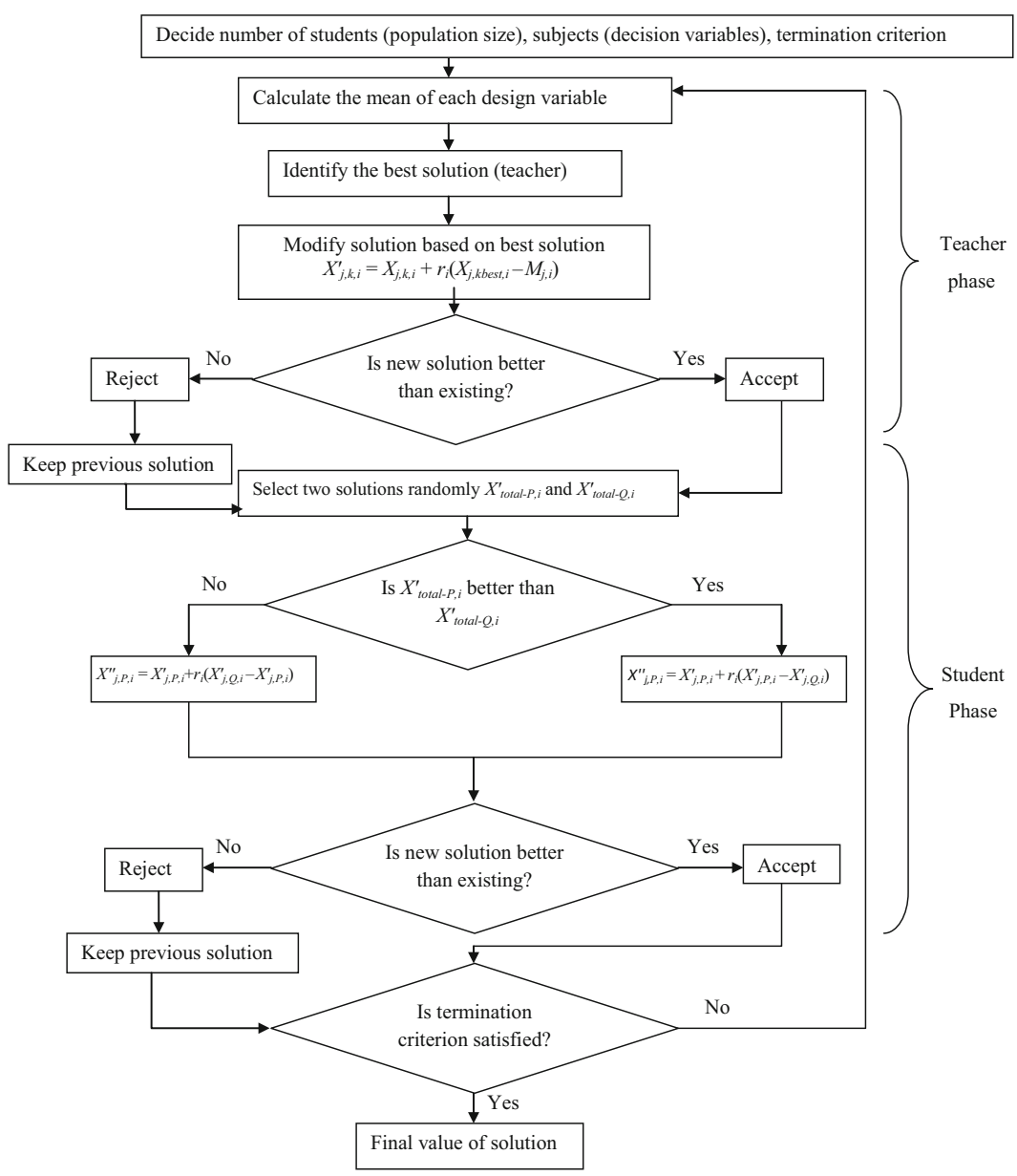

Figure 4. Flowchart of TLBO algorithm [32].

all weight values should be equal to 1 . Equal weights are considered in this problem for demonstration, i.e. $w_{1}=w_{2}=w_{3}=1 / 3$. The values of $Z_{1 \max }, Z_{2 \max }$ and $Z_{3 \min }$ are the maximum power, maximum efficiency and minimum pressure loss respectively, which are obtained by individually considering the respective single objective functions (ignoring the other objective functions) and solving the considered individual objective function under the same constraints. The values of $Z_{1 \text { max }}, Z_{2 \max }$ and $Z_{3 \text { min }}$ are shown in table 1 and these are obtained by applying the TLBO algorithm considering the individual objective functions under the same constraints.

\section{Results}

The case study considered in this paper is adopted from Ahmadi et al [23]. The objective functions, constraints and the ranges of variables considered in the present work are same as those considered by Ahmadi et al [23]. The range of speed is $1200 \mathrm{rpm}$ to $3000 \mathrm{rpm}$ and the range of temperature of heat source is $800-1300 \mathrm{~K}$ and the range of piston diameter is from 50 to $140 \mathrm{~mm}$. The specifications of the Stirling engine are considered as given below [23]:

$$
\begin{aligned}
N & =8, v=3.249 \times 10^{-5}\left(\mathrm{~m}^{2} / \mathrm{s}\right), \gamma=1.667, C_{\mathrm{v}}=3115.6 \\
& \times\left(\mathrm{J} \mathrm{kg}^{-1} \mathrm{~K}^{-1}\right), P_{\mathrm{r}}=0.71, m_{\mathrm{g}}=0.001135(\mathrm{~kg}), \\
& \rho_{\mathrm{st}}=8030\left(\mathrm{~kg} \mathrm{~m}^{-3}\right), C_{\mathrm{pg}}=5193\left(\mathrm{~J} \mathrm{~kg}^{-1} \mathrm{~K}^{-1}\right), \\
& C_{\mathrm{R}}=502.48\left(\mathrm{~J} \mathrm{~kg}^{-1} \mathrm{~K}^{-1}\right), \lambda=1.2, b=6.88 \times 10^{-5}, \\
& f=0.556, d=4 \times 10^{-5}(\mathrm{~m}) .
\end{aligned}
$$

Ahmadi et al [23] used NSAGA-II for achieving Pareto optimal frontier of three objective functions, output power, thermal efficiency of Stirling engines and system pressure loss. Each point on the Pareto frontier represents the optimal solution of the problem. The decision-making methods were used to find out the final optimal solution from the Pareto frontier which was gained through NSGA-II algorithm. Well-known decision-making procedures including the fuzzy Bellman-Zadeh, LINMAP and TOPSIS methods were used by Ahmadi et al [23] to select the best solution from among many Pareto optimal solutions given by the NSGA-II algorithm. The Bellman-Zadeh procedure 
Table 1. Optimization results obtained by TLBO algorithm for Stirling heat engine.

\begin{tabular}{lcc}
\hline Objective functions & $\begin{array}{c}\text { Optimum value of the objective function } \\
\text { when attempted individually }\end{array}$ & $\begin{array}{c}\text { Optimum value of the objective function when the combined } \\
\text { objective function is attempted }\end{array}$ \\
\hline $\begin{array}{l}\text { Maximization of power } \\
(\mathrm{kW})\end{array}$ & 15.62 & 6.89 \\
$\begin{array}{l}\text { Maximization of thermal } \\
\text { efficiency (\%) }\end{array}$ & 22.01 & 15.07 \\
$\begin{array}{l}\text { Minimization of total } \\
\text { power loss (kPa) }\end{array}$ & 11.65 & 18.70 \\
\hline
\end{tabular}

implements the fuzzy non-dimensionalization, while the other methods (i.e. LINMAP and TOPSIS) used Euclidian non-dimensionalization.

The proposed TLBO algorithm is now applied to the multiobjective optimization (containing three objectives) of power Stirling heat engine problem. The number of function evaluations required by TLBO algorithm is equal to 4000 . The output power and thermal efficiency of the Stirling engine are maximized along with the minimization of the pressure losses of the Stirling engine simultaneously. Table 1 shows the optimum values of the three objective functions when they were attempted individually (i.e. considering only one objective at a time ignoring the other objectives but considering the same set of constraints) and combinedly (i.e. considering the combined objective function and solving the same for the same set of constraints). It may be observed that optimum values of the individual objective functions are better than those when attempted simultaneously. It is due to the reason that an increase or decrease in the value of one objective may lead to decrease or increase in the value of another objective. This happens in multi-objective optimization problems and the values of the three objective functions obtained by solving the combined objective function represent the compromise solutions, i.e. these are the solutions obtained by satisfying all the constraints considering all the objectives simultaneously.

Table 2 shows the comparison of optimal results of power Stirling heat engine obtained by using TLBO algorithm, TOPSIS method, LINMAP method, fuzzy BellmanZadeh method and experimental results of Petrescu et al [17]. Petrescu et al [17] compared the analytical results with experimental results. Two objectives namely; output power and thermal efficiency of Stirling engines were considered. However, Petrescu et al [17] had not considered the system pressure loss in their work. They showed the accurate analysis of the performance in terms of power and efficiency for Stirling engines over a range of conditions. In table 2 the values of $\Delta T_{\mathrm{L}}$ and $\Delta T_{\mathrm{H}}$ are missing corresponding to experimental results because these values are related to system pressure loss and were not considered by Petrescu et al [17].

It may be observed from table 2 that the optimum values of the design variables suggested by Ahmadi et al
[23] using TOPSIS and LINMAP methods are exactly same. The results of optimization using TLBO algorithm have given the optimum values of engine's rotation speed $\left(n_{\mathrm{r}}\right)$ as $1800 \mathrm{rpm}$, which is lower than the speeds suggested by other methods. The optimum value of mean effective pressure $\left(P_{\mathrm{m}}\right)$ is $2585.83 \mathrm{kPa}$ which is higher than that given by other methods except the experimental results. The optimum value of stroke $(s)$ is $60 \mathrm{~mm}$ which is almost same as that given by other methods except the experimental results. The optimum value of temperature of heat source $\left(T_{\mathrm{H}}\right)$ is $1200 \mathrm{~K}$ which is higher than those given by other methods. As compared to the results given by other methods and experimental results, the optimum values obtained by TLBO algorithm for the temperature of heat sink $\left(T_{\mathrm{L}}\right)$ and temperature difference between heat sink and working fluid $\left(\Delta T_{\mathrm{L}}\right)$, number of gauzes of the matrix $\left(N_{\mathrm{R}}\right)$ and piston diameter $\left(D_{\mathrm{C}}\right)$ are comparatively higher.

The optimum value of the temperature difference between heat source and working fluid $\left(\Delta T_{\mathrm{H}}\right)$ is lower than those given by the other methods. The optimum value of regenerator's length $(L)$ is $71 \mathrm{~mm}$ which is almost similar to those given by the other methods, but much higher than that given by the experimental results of Petrescu et al [17]. The optimum value of regenerator diameter $\left(D_{\mathrm{R}}\right)$ is $60 \mathrm{~mm}$ and this is almost similar to those given by the other methods, but lower than that given by Petrescu et al [17]. The optimum values suggested by the application of TLBO algorithm are well within the given ranges of the variables considered by Ahmadi et al [23]. Thus, the values of power, efficiency and pressure losses obtained by the TLBO algorithm are meaningful as the obtained values of the design variables satisfy the constraints and these constraints are nothing but the ranges of variables.

It is observed from table 2 that the optimum values of the three objective functions suggested by the TLBO algorithm by solving the multi-objective optimization problem (by converting it into a combined objective function) are better than those suggested by the other methods and the experimental approach. For the maximum power, the results obtained by using the TLBO algorithm are 74.05, 18.02 and $42.54 \%$ better than those given by the TOPSIS and LINMAP methods, fuzzy Bellman-Zadeh method and 
Table 2. Optimization results for Stirling heat engine.

\begin{tabular}{|c|c|c|c|c|c|c|c|c|c|c|c|c|c|c|}
\hline & \multirow{2}{*}{\multicolumn{11}{|c|}{ Decision variables }} & \multicolumn{3}{|c|}{ Objective functions } \\
\hline & & & & & & & & & & & & \multirow{2}{*}{$\begin{array}{c}Z 1 \\
\text { Power } \\
(\mathrm{kW})\end{array}$} & \multirow{2}{*}{$\begin{array}{c}22 \\
\eta(\%)\end{array}$} & \multirow{2}{*}{$\begin{array}{c}Z 3 \\
\sum_{(k P a)} \Delta p_{\mathrm{i}}\end{array}$} \\
\hline & $\begin{array}{c}n_{\mathrm{r}} \\
(\mathrm{rpm})\end{array}$ & $\begin{array}{c}\mathrm{Pm} \\
(\mathrm{kPa})\end{array}$ & $S(\mathrm{~mm})$ & $\begin{array}{l}T_{\mathrm{H}} \\
(\mathrm{K})\end{array}$ & $T_{\mathrm{L}}(\mathrm{K})$ & $\begin{array}{l}\Delta T_{\mathrm{H}} \\
(\mathrm{K})\end{array}$ & $\begin{array}{c}\Delta T_{\mathrm{L}} \\
(\mathrm{K})\end{array}$ & $N_{\mathrm{R}}$ & $L(\mathrm{~mm})$ & $\begin{array}{c}D c \\
(\mathrm{~mm})\end{array}$ & $\begin{array}{c}D_{\mathrm{R}} \\
(\mathrm{mm})\end{array}$ & & & \\
\hline TOPSIS [23] & 2120 & 2550.3 & 60.5 & 989.6 & 298.4 & 74.4 & 11.8 & 339 & 70 & 101.6 & 59.5 & 6.076 & 14.56 & 19.69 \\
\hline LINMAP [23] & 2120 & 2550.3 & 60.5 & 989.6 & 298.4 & 74.4 & 11.8 & 339 & 70 & 101.6 & 59.5 & 6.076 & 14.56 & 19.69 \\
\hline $\begin{array}{l}\text { Fuzzy Bellman- } \\
\text { Zadeh [23] }\end{array}$ & 2056 & 2437 & 60.5 & 989.3 & 299.5 & 76.4 & 12.1 & 338 & 71.8 & 106.1 & 58.9 & 5.84 & 14.51 & 18.82 \\
\hline $\begin{array}{l}\text { Experimental } \\
\text { results [17] }\end{array}$ & 2500 & 4130 & 100 & 977 & 288 & - & - & 308 & 22.6 & 22.6 & 69.9 & 3.96 & 12.7 & - \\
\hline $\begin{array}{l}\text { TLBO (present } \\
\text { work) }\end{array}$ & 1800 & 2585.83 & 60 & 1200 & 300.87 & 64.2 & 13.5 & 350 & 71 & 122.2 & 60 & 6.89 & 15.07 & 18.70 \\
\hline
\end{tabular}

The numbers in bold indicate better values.

experimental results respectively. In maximization of thermal efficiency $(\eta)$, the results obtained by using the TLBO algorithm are $3.5,3.85$ and $18.66 \%$ better than the TOPSIS and LINMAP methods, fuzzy Bellman-Zadeh method and experimental result respectively. Similarly, in minimization of total power loss $\left(\sum \Delta p_{\mathrm{i}}\right)$, the results obtained by using the TLBO algorithm are 5.02 and $0.679 \%$ better than the TOPSIS and LINMAP methods and fuzzy Bellman-Zadeh method respectively.

Figure 5 shows the convergence of the TLBO algorithm for single objective optimization of Stirling heat engine problem. It shows the convergence rate of the TLBO algorithm for the power $(P)$, efficiency $(\eta)$ and pressure losses $\left(\sum \Delta P_{\mathrm{i}}\right)$ when considering the individual objectives and the convergence takes place after 15th, 19th and 12th iteration of the TLBO algorithm, respectively. Figure 6 shows the convergence rate of the TLBO algorithm for the combined objective function and the convergence takes place after 7 th iteration of TLBO algorithm. It may be observed that the TLBO algorithm takes less number of iterations for convergence.

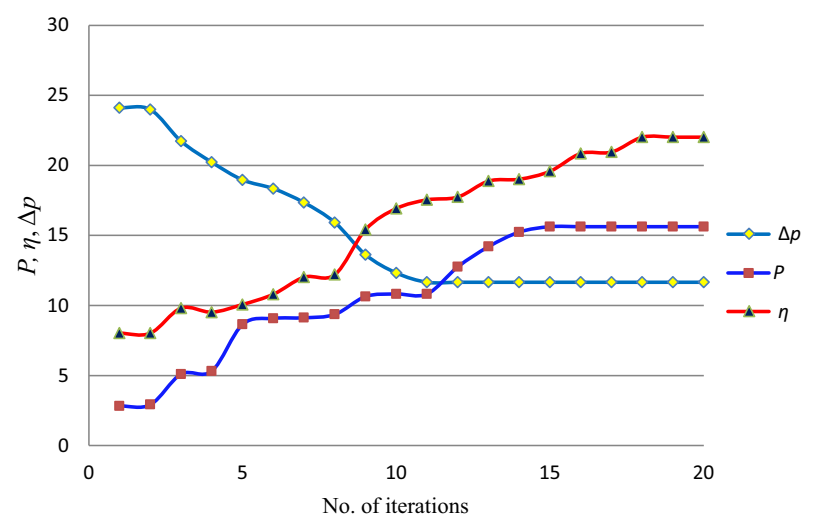

Figure 5. Convergence graphs of TLBO algorithm for power, thermal efficiency and pressure losses.
Figure 7 shows the effects of the design variables on the three objectives, i.e. $P, \eta$ and $\sum \Delta P_{\mathrm{i}}$ of Stirling engine. It may be observed that increasing mean effective pressure increases $P$ and $\eta$ and slightly decreases $\sum \Delta P_{\mathrm{i}}$ (figure $7(\mathrm{a})$ ). Increasing engine speed decreases $\eta$ and increases $\sum \Delta P_{\mathrm{i}}$ and $P$ first increases then decreases and again increases with increasing engine speed (figure 7(b)). The $\sum \Delta P_{\mathrm{i}}$ increases with the increase in stroke, however, the $\eta$ increases only slightly and the $P$ remains almost constant with increase in the stroke (figure $7(\mathrm{c})$ ). The $P, \eta$ and the $\sum \Delta P_{\mathrm{i}}$ increase with the temperature of heat source (figure $7(\mathrm{~d})$ ) and decrease with the temperature of heat sink (figure 7(e)). The values of $\eta$ and $\sum \Delta P_{\mathrm{i}}$ almost remain constant and $P$ decreases with increasing temperature difference of heat source and working fluid (figure 7(f)). The values of $\eta$ and $P$ remain constant and the value of the $\sum \Delta P_{\mathrm{i}}$ slightly decreases with increasing temperature difference of heat sink and working fluid (figure $7(\mathrm{~g})$ ). Figures $7(\mathrm{~h}-$ k) show that the values of $P$ and $\sum \Delta P_{\mathrm{i}}$ remain almost constant and $\eta$ increases with increasing number of gauzes of the matrix, regenerator's length, piston diameter and regenerator diameter.

It is observed that in the case of power $P$, the most important design variables are mean effective pressure $\left(P_{\mathrm{m}}\right)$, engine speed $\left(n_{\mathrm{r}}\right)$, temperature of heat source $\left(T_{\mathrm{H}}\right)$ and temperature difference of heat source and working fluid $\left(\Delta T_{\mathrm{H}}\right)$. Similarly, in the case of efficiency $\eta$, the important design variables are mean effective pressure $\left(P_{\mathrm{m}}\right)$, engine speed $\left(n_{\mathrm{r}}\right)$, temperature of heat source $\left(T_{\mathrm{H}}\right)$, temperature of heat sink $\left(T_{\mathrm{L}}\right)$, temperature difference of heat source and working fluid $\left(\Delta T_{\mathrm{H}}\right)$, regenerator's length $(L)$ and regenerator diameter $\left(D_{\mathrm{R}}\right)$. In the case of pressure losses $\sum \Delta P_{\mathrm{i}}$, the important design variables are engine speed $\left(n_{\mathrm{r}}\right)$, stroke $(s)$, temperature of heat sink $\left(T_{\mathrm{H}}\right)$ and temperature of heat sink $\left(T_{\mathrm{L}}\right)$. It is observed that the TLBO algorithm gives better results than the TOPSIS, LINMAP, fuzzy Bellman-Zadeh method and the experimental results. 


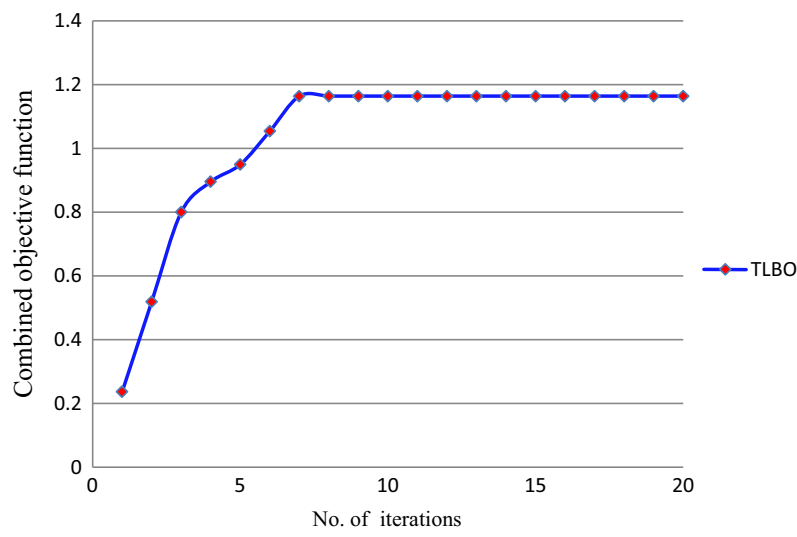

Figure 6. Convergence graph of the TLBO algorithm for the combined objective function.

\section{Conclusions}

Multi-objective optimization is a very important research area in engineering studies, because of real-world design problems that require the optimization of a group of objectives. Multiple, often conflicting, objectives arise naturally in most real-world optimization scenarios. Adding more than one objective to an optimization problem adds complexity. In this paper, three different objective functions are considered for optimization of the design of the Stirling heat engine. The three different objective functions considered are maximum power, maximum thermal efficiency and minimum pressure loss. The experimental results and the mathematical models for the design of Stirling engine which were earlier attempted by other researchers are considered in the present work. For optimization of design of Stirling heat engine, a recently developed advanced optimization algorithm namely, teaching-learning-based optimization (TLBO) algorithm, is considered. As the TLBO is an algorithm-specific parameter-less algorithm, the performance of this technique is not affected by the algorithm parameters. It makes this algorithm applicable to real life optimization problems, easily and effectively.

The TLBO algorithm has shown its ability in solving the individual objective functions as well as multi-objective optimization problem by using a combined objective function. The convergence behaviour of the TLBO algorithm to a near global solution is observed in less number of iterations and the algorithm more effective than the decision making methods of TOPSIS, LINMAP and fuzzy Bellman-Zadeh that have used the results of NSGA-II algorithm to select the best optimum values of the design variables and the objective functions. The optimum results suggested by the TLBO algorithm are also better than those given by the experimental results. The TLBO algorithm can be quite promising and a reliable choice for the optimization of design of the Stirling heat engine. The output of this work may help the designer to make effective use TLBO
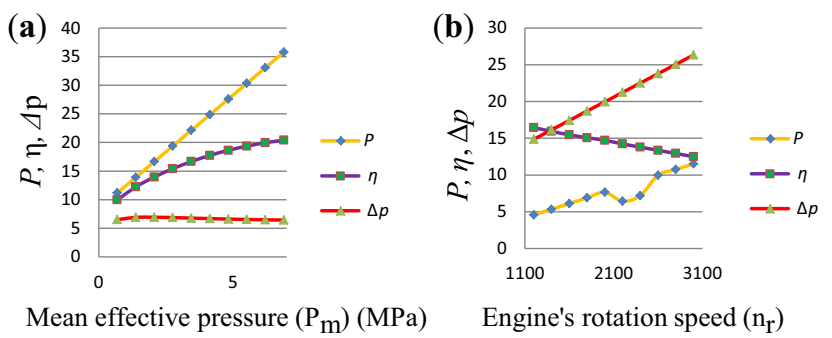

Mean effective pressure $\left(\mathrm{P}_{\mathrm{m}}\right)(\mathrm{MPa})$
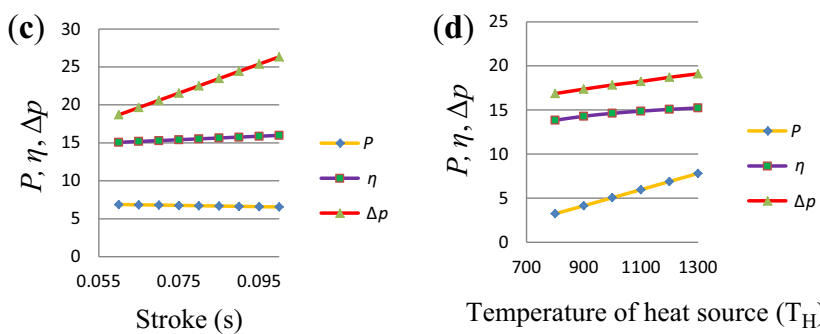

Temperature of heat source $\left(\mathrm{T}_{\mathrm{H}}\right)$

(e)

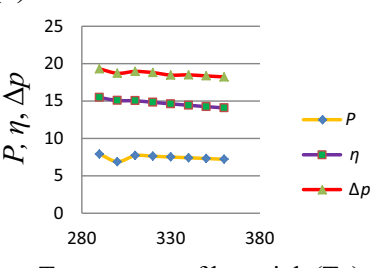

(f)

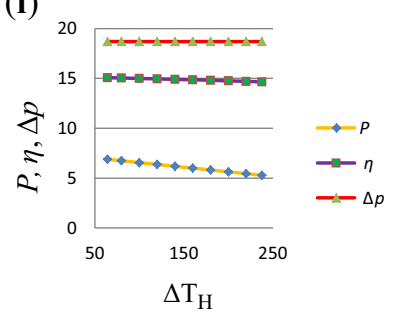

(g)

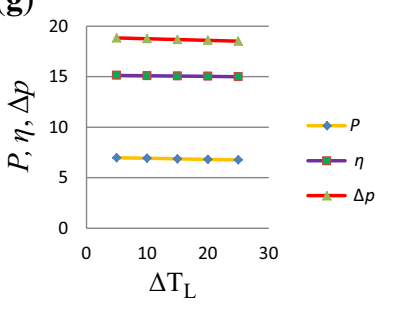

(h)

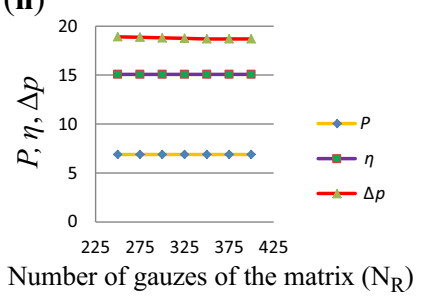

(i)

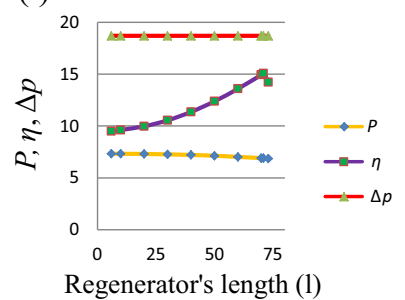

(j)

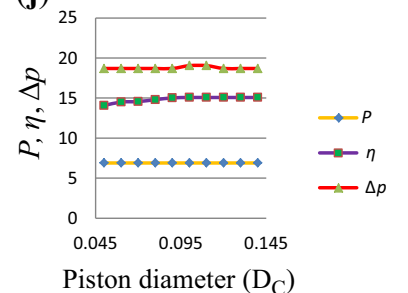

(k)

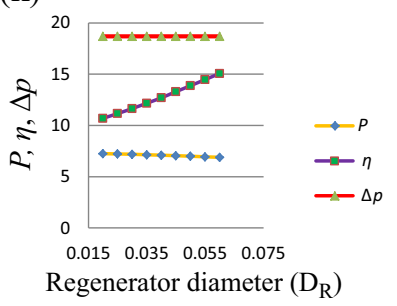

Figure 7. (a-k) Effects of design variables on power, efficiency and pressure losses of Stirling engine. 
algorithm for the design optimization of other heat engines. The application of the TLBO algorithm may be extended to solve multi-objective optimization problems of different thermal engineering systems and devices.

\section{Nomenclature}

$b \quad$ coefficient $(0,2)$

$C_{\mathrm{v}} \quad$ constant volume specific heat

$D \quad$ diameter (m)

$d \quad$ wire diameter $(\mathrm{m})$

$f \quad$ coefficient related to the friction contribution $(0,1)$

$h \quad$ heat transfer coefficient $\left(\mathrm{W} \mathrm{m}^{-2} \mathrm{~K}^{-1}\right)$

$m$ mass of the gas

$N \quad$ number of gauzes of the matrix, number of regenerators per cylinder

$n_{\mathrm{r}} \quad$ rotation speed

$p \quad$ pressure

$\Delta p \quad$ pressure loss

$P \quad$ output power

$\dot{Q}$ heat transfer rate

$R \quad$ gas constant

$s \quad$ stroke

$T \quad$ temperature

$\Delta T \quad$ temperature difference

$i \quad$ ith objective

$j \quad$ jth solution

$X \quad$ vector of decision variables, regenerative losses coefficient

$n_{\mathrm{r}} \quad$ engine's rotation speed

$P_{\mathrm{m}} \quad$ mean effective pressure

$T_{\mathrm{H}} \quad$ temperature of heat source

$T_{\mathrm{L}} \quad$ temperature of heat sink

$\Delta T_{\mathrm{L}} \quad$ temperature difference between heat source and working fluid

$\Delta T_{\mathrm{H}} \quad$ temperature difference between heat sink and working fluid

$L \quad$ regenerator's length

$D_{\mathrm{C}} \quad$ piston diameter

$D_{\mathrm{R}} \quad$ regenerator diameter

$A_{\mathrm{R}}$ regenerator area

\section{Greek letters}

$\lambda \quad$ ratio of volume during the regenerative processes (volumetric ratio)

$\varepsilon R$ effectiveness of the regenerator

$\eta \quad$ efficiency

$\eta_{c} \quad$ Carnot efficiency

$\gamma \quad$ specific heat ratio

$\mu$ fuzzy membership function

$\varepsilon \quad$ emissivity factor

$\delta$ the Stefan's constant $v \quad$ viscosity of the working gas $\left(\mathrm{m}^{2} \mathrm{~s}^{-1}\right)$

\section{Subscripts}

c cylinder, related to the Carnot cycle

$f \quad$ friction

$H \quad$ heat source

$L \quad$ heat sink

$\mathrm{R}$ regenerator

SE Stirling engine

II related to the second law

1-4 the processes states

$g \quad$ gas

aver average

$m$ mean, the system

app collector aperture

throat throttling

\section{References}

[1] Minassians A D and Sanders S R 2011 Stirling engines for distributed low-cost solar-thermal-electric power generation. J. Solar Energy Eng. 133: 223-235

[2] Kongtragool B and Wongwise S 2007 A review of solarpowered Stirling engines and low temperature differential Stirling engines. Renew. Sust. Energy Rev. 7: 131-154

[3] Markman M A, Shmatok Y I and Krasovkii V G 1983 Experimental investigation of a low-power Stirling engine. Geliotekhnika 19: 19-24

[4] Orunov B, Trukhov V S and Tursunbaev I A 1983 Calculation of the parameters of a symmetrical rhombic drive for a single-cylinder Stirling engine. Geliotekhnika 19: 29-33

[5] Abdalla S and Yacoub S H 1987 Feasibility prediction of potable water production using waste heat from refuse incinerator hooked up at Stirling cycling machine. Desalination 64: 491-500

[6] Hirata K, Iwamoto S, Toda F and Hamaguchi K 1997 Performance evaluation for a $100 \mathrm{~W}$ Stirling engine. In: Proceedings of 8th International Stirling Engine Conference, pp. $19-28$

[7] Costea M and Feidt M 1998 The effect of the overall heat transfer coefficient variation on the optimal distribution of the heat transfer surface conductance or area in a Stirling engine. Energy Convers. Manag. 39: 1753-63

[8] Wu F, Chen L, Sun F, Wu C and Zhu Y 1998a Performance and optimization criteria for forward and reverse quantum Stirling cycles. Energy Convers. Manag. 39: 733-739

[9] Wu F, Chen L, Wu C and Sun F 1998b Optimum performance of irreversible Stirling engine with imperfect regeneration. Energy Convers. Manag. 39: 727-732

[10] Costea M, Petrescu S and Harman C 1999 The effect of irreversibilities on solar Stirling engine cycle performance. Energy Convers. Manag. 40: 1723-1731 
[11] $\mathrm{Wu} \mathrm{F}$, Chen L and Wu C 2000 Finite-time exergoeconomic performance bound for a quantum Stirling engine. Int. J. Eng. Sci. 38: 239-247

[12] Organ A J 2000 Stirling air engine thermodynamic appreciation. Proc. IMech E, Part C: J. Mech. Eng. Sci. 214: 511-536

[13] Kaushik S C and Kumar S 2000 Finite time thermodynamic analysis of endoreversible Stirling heat engine with regenerative losses. Energy 25: 989-1003

[14] Kaushik S C and Kumar S 2001 Finite time thermodynamic evaluation of irreversible Ericsson and Stirling heat engines. Energy Convers. Manag. 42: 295-312

[15] Gu Z, Sato H and Feng X 2001 Using supercritical heat recovery process in Stirling engines for high thermal efficiency. Appl. Therm. Eng. 21: 1621-1630

[16] Hsu S T, Lin F Y and Chiou J S 2003 Heat-transfer aspects of Stirling power generation using incinerator waste energy. Renew. Energy 28: 59-69

[17] Petrescu S, Costea M, Harman C and Florea T 2002 Application of the direct method to irreversible Stirling cycles with finite speed. Int. J. Energy Res. 26: 589-609

[18] Martaj N, Grosu L and Rochelle P 2007 Thermodynamic study of a low temperature difference Stirling engine at steady state operation. Int. J. Therm. 10(4): 165-176

[19] Timoumi Y, Tlili I and Ben N S 2008 Design and performance optimization of GPU-3 Stirling engines. Energy 33(7): 1100-1114

[20] Formosa F and Despesse G 2010 Analytical model for Stirling cycle machine designs. Energy Convers. Manag. 51: $1855-1863$

[21] Li Y, Yaling H and Weiwei W 2011 Optimization of solarpowered Stirling heat engine with finite-time thermodynamics. Renew. Energy 36: 421-427

[22] Tlili I 2012 Finite time thermodynamic evaluation of endoreversible Stirling heat engine at maximum power conditions. Renew. Sust. Energy Rev. 16(4): 2234-2241
[23] Ahmadi M H, Hosseinzade H, Sayyadi H, Mohammadi A H and Kimiaghalam F 2013a Application of the multi-objective optimization method for designing a powered Stirling heat engine: Design with maximized power, thermal efficiency and minimized pressure loss. Renew. Energy 60: 313-322

[24] Ahmadi M H, Mohammadi A H and Saeed D 2013b Evaluation of the maximized power of a regenerative endoreversible Stirling cycle using the thermodynamic analysis. Energy Convers. Manag. 76: 561-570

[25] Ahmadi M H, Sayyadi H, Mohammadi A H and Marco A B 2013c Thermo-economic multi-objective optimization of solar dish-Stirling engine by implementing evolutionary algorithm. Energy Convers. Manag. 73: 370-380

[26] Ahmadi M H, Mohammadi A H, Saeed D and Marco A B 2013d Multi-objective thermodynamic-based optimization of output power of Solar Dish-Stirling engine by implementing an evolutionary algorithm. Energy Convers. Manag. 75: 438-445

[27] Rao R V and More K C 2015 Optimal design of the heat pipe using TLBO (teaching-learning-based optimization) algorithm. Energy 80: 535-544

[28] Rao R V 2016 Teaching learning based optimization algorithm and its engineering applications. London: SpringerVerlag.

[29] Rao R V, Savsani V J and Vakharia D P 2011 Teachinglearning-based optimization: A novel method for constrained mechanical design optimization problems. Comp.-Aided Des. 43: 303-315

[30] Reader G T and Hooper C 1988 Stirling engines. Cambridge: University Press

[31] Petrescu S, Petre C, Costea M, Malancioiu O, Boriaru N and Dobrovicescu A 2010 A methodology of computation, design and optimization of solar Stirling power plant using hydrogen/oxygen fuel cells. Energy 35(2):729-39

[32] Rao R V and More K C 2014 Advanced optimal tolerance design of machine elements using teaching-learning-based optimization algorithm. Prod. Manuf. Res. 2(1): 71-94 